Respiration 2016;92:58-60

DOI: $10.1159 / 000447641$

\section{Antimuscarinic Bronchodilator Response Retained after Bronchoscopic Vagal Denervation in Chronic Obstructive Pulmonary Disease Patients}

\author{
Coenraad Frederik N. Koegelenberg ${ }^{\mathrm{a}}$ Johan Theron $^{\mathrm{b}}$ \\ Dirk-Jan Slebos ${ }^{c}$ Karin Klooster ${ }^{c}$ Martin Mayse ${ }^{d}$ \\ Reinoud Gosens ${ }^{e}$ \\ a Division of Pulmonology, Department of Medicine, \\ Stellenbosch University \& Tygerberg Academic Hospital, and \\ ${ }^{b}$ Panorama MediClinic, Cape Town, South Africa; ' Department \\ of Pulmonary Diseases, University Medical Centre Groningen, \\ University of Groningen, Groningen, The Netherlands; \\ ${ }^{\mathrm{d}}$ Holaira, Inc., Minneapolis, Minn., USA; ${ }^{\text {e Department of }}$ \\ Molecular Pharmacology, University of Groningen, \\ Groningen, The Netherlands
}

Acetylcholine from parasympathetic nerves remains a well-validated target to treat patients with chronic obstructive pulmonary disease (COPD). Current treatment guidelines recommend anticholinergics as first-line therapy for mild to advanced COPD [1]. Targeted lung denervation (TLD) is a novel bronchoscopic therapy that ablates the parasympathetic innervation of the lungs and has a similar proposed mechanism of action to anticholinergic drugs [2].

In the first-in-man non-randomized, uncontrolled, prospective, sequential, two-dose study (NCT01483534), we found TLD to be feasible, safe, and well tolerated [2]. In the original study, TLD was performed on COPD patients $\geq 40$ years of age with a ratio of the forced expiratory volume in $1 \mathrm{~s}\left(\mathrm{FEV}_{1}\right)$ to the forced vital capacity of $\leq 0.70$ and a postbronchodilator $\mathrm{FEV}_{1}$ of $30-60 \%$ of predicted normal values [2]. Patients had to have a smoking history of $\geq 10$ pack-years and no history of asthma [2]. Only patients with a $15 \%$ or greater relative increase in $\mathrm{FEV}_{1}$ following inhalation of $80 \mu \mathrm{g}$ ipratropium bromide were included in this study [2]. Patients underwent staged TLD at 20 or $15 \mathrm{~W}$ following baseline assessment off bronchodilators [2]. Assessments were repeated off bronchodilators (including antimuscarinics) at 30, 90, 180, 270, and 365 days after TLD.

Twelve patients $\left(\mathrm{FEV}_{1} 33.8 \pm 9.4 \%\right.$ predicted $)$ were treated at a 20 -watt energy dose and 10 patients $\left(\mathrm{FEV}_{1} 34.5 \pm 6.3 \%\right.$ predicted) at $15 \mathrm{~W}$. The clinical safety profiles were similar between the two energy doses. The results for the 20 -watt cohort suggest larger and more durable improvements in lung function $\left(\mathrm{FEV}_{1}\right.$ $+11.6 \%$ ), exercise capacity (submaximal cycle endurance +6.8 $\mathrm{min}$ ), and health-related quality of life (St. George's Respiratory Questionnaire -11.1) [2]. We subsequently aimed to investigate whether the antimuscarinic bronchodilator response was re- tained in patients with COPD who underwent TLD in the pilot study.

A post hoc analysis was performed to specifically assess the peak bronchodilator response (increase in $\mathrm{FEV}_{1}$ ) following inhalation of $80 \mu \mathrm{g}$ ipratropium, which was performed as part of the study at 90, 180, and 365 days. The bronchodilator response was measured at 30 and $60 \mathrm{~min}$ following the administration of ipratropium, and the peak was defined as the higher of the two values.

Categorical data were tabulated with counts and percentages. All available data were summarized, with no imputation for missing data. An independent statistical group (NAMSA, Minneapolis, Minn., USA) conducted the final analyses using SAS V.9.3 (SAS Institute, Cary, N.C., USA).

All 22 patients were included in the post hoc analysis. Six months' follow-up data were complete for all patients. One-year follow-up data were available in 11 of 12 patients in the 20 -watt cohort and in 9 of 11 patients in the 15-watt cohort.

The bronchodilator response achieved by $80 \mu \mathrm{g}$ ipratropium at peak at 90, 180, and 365 days after TLD is summarized in table 1 and figure 1 . Postbronchodilator $\mathrm{FEV}_{1}$ was significantly different from prebronchodilator $\mathrm{FEV}_{1}$ at all time points $(\mathrm{p}<0.05)$, implying that the bronchodilator response achieved by inhaled ipratropium at peak was not blunted in patients who underwent TLD. The greatest bronchodilator response was observed in patients treated with $20 \mathrm{~W}$, with a mean response of $355 \mathrm{ml}(42.8 \%)$ at 1-year follow-up.

Our findings suggest that simultaneous targeting of acetylcholine release and function by TLD and antimuscarinics provides additive bronchodilatory effects. Partial reinnervation of bisected efferent parasympathetic motor nerves is known to occur as is unstimulated low-grade constant release of acetylcholine at the postganglionic membranes, and both these effects may explain the interactive effects [3].

Our data also suggest that vagal denervation at the level of the main bronchi is unlikely to result in complete and permanent suppression of the distal parasympathetic nervous system in the airways. The impressive bronchodilation achieved by inhaled ipratropium in patients who underwent TLD strongly favours this postulation and also suggests that future research should focus on the combination of TLD and inhaled long-acting muscarinic antagonist.

An alternative explanation lies in the potential anti-inflammatory effects of TLD [4]. Our understanding of the parasympathetic innervation of the lungs as well as the role of acetylcholine release in health and diseased states has evolved over the last 2 decades. Acetylcholine production in the airways is now known not to be restricted to the parasympathetic nervous system. It is also released from non-neuronal sources such as the bronchial epithelium and inflammatory cells [5]. Evidence suggests that acetylcholine may play an integral role in regulating the mechanisms that drive the chronic airway inflammation in COPD [3-5]. Many other factors above and beyond the vagal nerve therefore influence the

\section{KARGER}

E-Mail karger@karger.com

www.karger.com/res
C 2016 S. Karger AG, Basel

0025-7931/16/0921-0058\$39.50/0
Coenraad Frederik N. Koegelenberg

Division of Pulmonology, Department of Medicine

Stellenbosch University \& Tygerberg Academic Hospital

PO Box 241, Cape Town 8000 (South Africa)

E-Mail coeniefn@sun.ac.za 
Table 1. The bronchodilator response achieved by $80 \mu \mathrm{g}$ ipratropium at peak at 90, 180, and 365 days after TLD

\begin{tabular}{|c|c|c|c|c|}
\hline Change in $\mathrm{FEV}_{1}$ from baseline & Pre-TLD & 90 days & 180 days & 365 days \\
\hline \multicolumn{5}{|l|}{$20 W$} \\
\hline \multicolumn{5}{|l|}{ TLD alone, prebronchodilator } \\
\hline Litre & & $0.085 \pm 0.073$ & $0.098 \pm 0.070$ & $0.049 \pm 0.088$ \\
\hline$\%$ & & $12.5 \pm 7.8$ & $13.5 \pm 7.2$ & $11.6 \pm 10.2$ \\
\hline \multicolumn{5}{|l|}{ Postbronchodilator } \\
\hline Litre & $0.265 \pm 0.043$ & $0.316 \pm 0.058$ & $0.259 \pm 0.089$ & $0.355 \pm 0.074$ \\
\hline$\%$ & $28.2 \pm 2.5$ & $36.7 \pm 4.9$ & $29.6 \pm 7.5$ & $42.8 \pm 6.5$ \\
\hline \multicolumn{5}{|l|}{$15 W$} \\
\hline \multicolumn{5}{|l|}{ TLD alone, prebronchodilator } \\
\hline Litre & & $0.030 \pm 0.039$ & $0.079 \pm 0.052$ & $-0.001 \pm 0.043$ \\
\hline$\%$ & & $2.9 \pm 4.7$ & $9.6 \pm 5.8$ & $0.0 \pm 4.8$ \\
\hline \multicolumn{5}{|l|}{ Postbronchodilator } \\
\hline Litre & $0.166 \pm 0.011$ & $0.232 \pm 0.042$ & $0.210 \pm 0.031$ & $0.123 \pm 0.045$ \\
\hline$\%$ & $19.8 \pm 0.6$ & $27.9 \pm 5.8$ & $24.5 \pm 4.0$ & $15.0 \pm 4.8$ \\
\hline
\end{tabular}

Data are shown as mean \pm standard error of the mean.

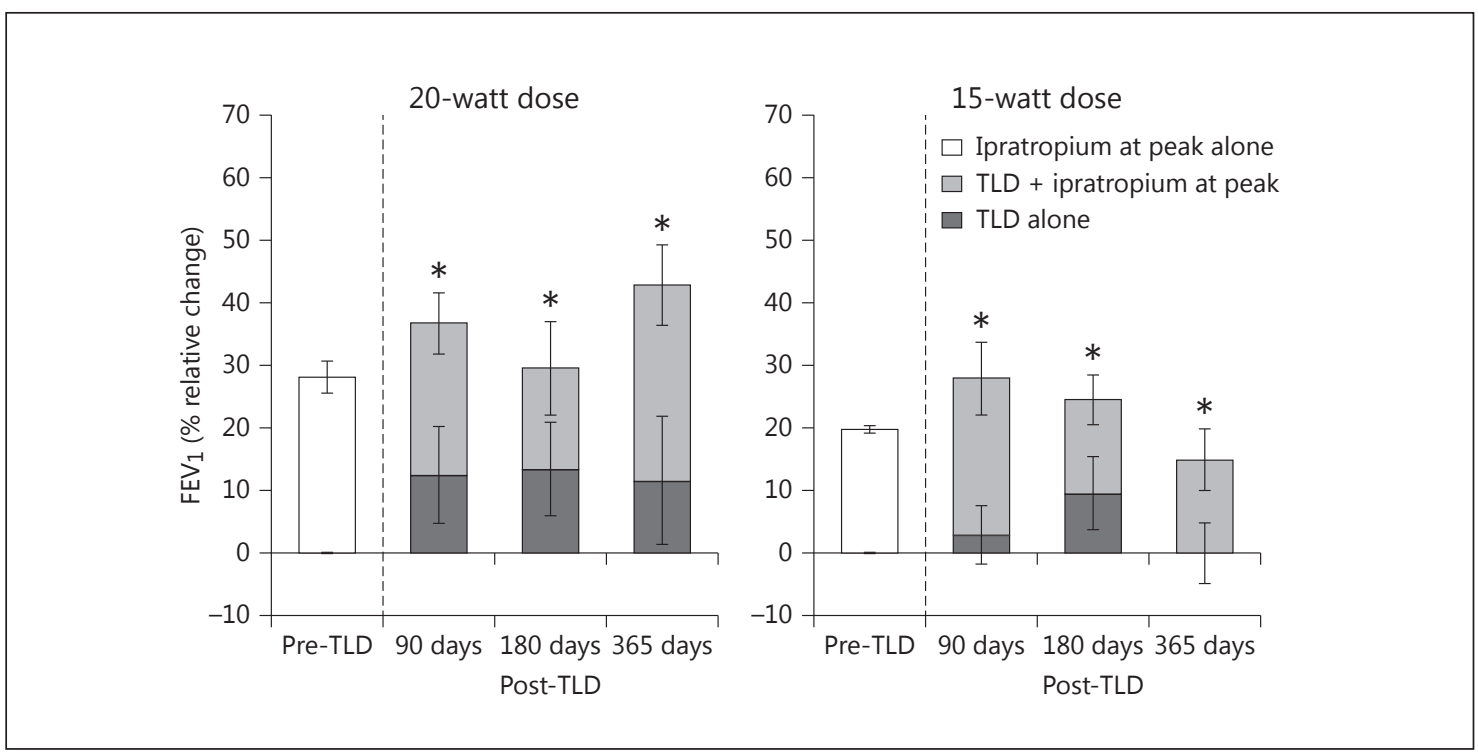

Fig. 1. Efficacy measures of TLD therapy plus inhaled ipratropium bromide $(80 \mu \mathrm{g})$ at peak. The change from baseline $\mathrm{FEV}_{1}$ off bronchodilators is shown as mean \pm standard error of the mean. Follow-up data were complete for all patients $(\mathrm{n}=22)$ until 180 days, and for 11 of 12 patients in the 20 -watt cohort, and for 9 of 11 pa-

parasympathetic tone in airways. Furthermore, afferent C-fibres, targeted by TLD as well, project to the subepithelial region where they can be activated by inflammatory mediators and non-specific stimuli. Activated C-fibres secrete neurokinins that exert local effects and facilitate ganglionic neurotransmission (as a peripheral reflex arc).

Bronchodilator Response after Vagal Denervation in COPD tients in the 15 -watt cohort at 1 year. Note that TLD plus ipratropium at peak was significantly different from TLD alone at all time points $\left({ }^{*} \mathrm{p}<0.05\right)$. TLD plus ipratropium at peak at all time points and ipratropium at peak pre-TLD were significantly different from baseline (pre-TLD, off bronchodilators; $\mathrm{p}<0.05$ ).

We excluded patients with a history of recurrent respiratory infections from the original study and allowed the use of inhaled corticosteroids during baseline testing and follow-up, which may be viewed as limitations when interpreting the post hoc analysis.

In conclusion, the bronchodilator response achieved by inhaled ipratropium was retained in patients who underwent TLD. 
Acknowledgments

We acknowledge the work of the late Chris T. Bolliger, MD, $\mathrm{PhD}$, for his important contributions in the collection of the data and Kristina T. Rouw, $\mathrm{PhD}$, for her role in the data analysis.

Financial Disclosure and Conflicts of Interest

All clinical trial expenses were reimbursed by the study sponsor (Holaira, Inc., Minneapolis, Minn., USA). M.M. is an employee of the study sponsor. D.-J.S. reports grants, personal fees, and nonfinancial support from Holaira Inc. during the conduct of the study.

\section{References}

1 Qaseem A, Wilt T, Weinberger S, et al: Diagnosis and management of stable chronic obstructive pulmonary disease: a clinical practice guideline update from the ACP, ACCP, ATS and ERS. Ann Intern Med 2011; 155:179-191.

-2 Slebos DJ, Klooster K, Koegelenberg CF, et al: Targeted lung denervation for moderate to severe COPD: a pilot study. Thorax 2015;70:411-419.

-3 Gosens R, Zaagsma J, Meurs H, Halayko AJ: Muscarinic receptor signaling in the pathophysiology of asthma and COPD. Respir Res 2006;7:73.

-4 Kistemaker LE, Slebos DJ, Meurs H, Kerstjens HA, Gosens R: Anti-inflammatory effects of targeted lung denervation in patients with COPD. Eur Respir J 2015;46:1489-1492.

5 Profita M, Albano GD, Riccobono L, et al: Increased levels of Th17 cells are associated with non-neuronal acetylcholine in COPD patients. Immunobiology 2014;219:392-401. 